\title{
Evaluation of the effect of intravenous ibuprofen use on postoperative pain and opioid consumption after abdominoplasty operation
}

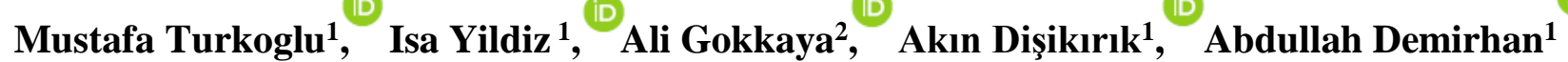

${ }^{I}$ Department of Anesthesiology and Reanimation, Bolu Abant Izzet Baysal University, Faculty of Medicine, Bolu, Turkey

${ }^{2}$ Department of Plastic and Aesthetic Surgery, Bolu Abant Izzet Baysal University, Faculty of Medicine, Bolu, Turkey

\section{ABSTRACT}

Aim: Abdominoplasty is a common cosmetic procedure that is one of the most painful aesthetic surgery and has been used increasingly in recent years. Ibuprofen is a non-steroidal anti-inflammatory (NSAID) with antipyretic and analgesic effects. In this study, we aimed to evaluate the effectiveness of the intravenous (IV) form of ibuprofen on postoperative pain control and opioid requirement in patients who underwent abdominoplasty.

Methods: The patients were divided into 3 groups as Group 1 (Tramadol), Group 2 (Ibuprofen) and Group 3 (Tramadol HCL + Ibuprofen). Tramadol HCL was given continuous infusion at a concentration of $4 \mathrm{mg} / \mathrm{ml}$ via IV Patient Controlled Analgesia to Group 1. Ibuprofen $800 \mathrm{mg} \mathrm{IV} \mathrm{was} \mathrm{administered} \mathrm{to} \mathrm{Group} 2$ at 30 minutes before the end of the operation. Patients were followed up by administering $800 \mathrm{mg}$ IV every 6 hours for 24 hours. In Group 3, 30 minutes before the end of the operation, tramadol was administered via PCA with continuous infusion at a concentration of $4 \mathrm{mg} / \mathrm{ml}$ and $800 \mathrm{mg}$ IV ibuprofen was administered as $4 \mathrm{x} 1$.

Results: VAS values were found to be significantly lower in Group 3 compared to Group 2 at every hour and at the 4th hour compared to Group 1. Group 3 was found to be significantly lower than Group 1 in total analgesic consumption in all time zones.

Conclusion: We think that IV ibuprofen, which will be given in addition to tramadol after abdominoplasty, can provide effective analgesia and reduce analgesic consumption.

Key words: Abdominoplasty, postoperative pain, ibuprofen, opioids.

$\triangle$ Dr. Isa Yildiz

Department of Anesthesiology and Reanimation, Bolu Abant Izzet Baysal University, Faculty of Medicine, Bolu, Turkey

E-mail: dr.isayildiz@hotmail.com

Received: 2021-09-28

Accepted: 2021-11-15

Published online: 2022-01-01

\section{Introduction}

Abdominoplasty surgery is an operation that aims to improve the contour of the abdominal wall by removing excess skin and fat from the abdominal region, rectus sheath plication and umbilical transposition [1]. Abdominoplasty is one of the most painful procedures in aesthetic surgery and has been used increasingly in recent years [2].

Effective management of postoperative analgesia can prevent many of the complications, such as respiratory, cardiovascular complications, delayed mobilization, and prolonged hospitalization [3]. Safe and effective postoperative pain control for abdominoplasties can result in early mobilization, shorter hospital stay, reduced 
hospital costs, quicker return to normal activities, and increased patient satisfaction [4]. Pharmacological and regional methods can be used for pain control after abdominoplasty. Patient-controlled analgesia (PCA), nonsteroidal anti-inflammatory drugs (NSAID), opioids, multimodal analgesia are among these methods [5]. Patient-controlled analgesia is a closed-circuit system that allows the patient to self-inject drugs as needed and not exceeding a certain amount. PCA applications in the treatment of postoperative pain are more effective than conventional analgesia methods and are frequently preferred today due to higher patient satisfaction, less sedation, less postoperative complications and positive contributions to the healing process of the patients [6].

Although opioids are widely used in postoperative pain management, they do not block the pain-inflammation relationship [7]. Therefore, non-steroidal anti-inflammatory drugs are used together with opioids for postoperative pain management. NSAIDs block the conversion of arachidonic acid to prostaglandins and inhibit the response of pain receptors to injury [8]. Multimodal analgesia therapy can reduce the total amount of opioids required, and opioid-related side effects can be minimized by effectively treating pain [9]. Ibuprofen is an NSAID with anti-inflammatory, antipyretic and analgesic effects [10]. The oral form of the drug has been used safely for a long time and is one of the most preferred NSAIDs. Ibuprofen has been shown to be effective in the treatment of post-operative pain.

In this study, we aimed to evaluate the effectiveness of the intravenous (IV) form of ibuprofen on postoperative pain control and opioid requirement in patients undergoing abdominoplasty.

\section{Materials and methods}

After the approval of Bolu Abant İzzet Baysal University Clinical Studies Ethics Committee dated 04/08/2020 and numbered 2020/190, 60 patients at risk of ASA I-II between the ages of 18-65 who were scheduled for elective abdominoplasty were included in the study.

The patients were divided into 3 groups by the randomized, prospective and closed envelope method. In Group 1 (Tramadol), Tramadol HCL (Tramosel 100 mg / 2 ml Haver Pharma Drugs Inc, Istanbul) was given continuous infusion at a concentration of $4 \mathrm{mg} / \mathrm{ml}$ via IV Patient Controlled Analgesia. Doses that could be administered $20 \mathrm{mg}$ of tramadol HCL at each push with a lock-in interval of 20 minutes were adjusted. The patient was instructed to press the button whenever he had pain. In Group 2, 800 mg IV Ibuprofen (Dorifen $800 \mathrm{mg} / 8 \mathrm{ml}$ VEM Drugs Inc., Turkey) was administered 30 minutes before the end of the operation. Patients were followed up by administering 800 mg IV every 6 hours for 24 hours. In Group 3 (Ibuprofen + Tramadol), 30 minutes before the end of the operation, tramadol was administered via PCA at a concentration of $4 \mathrm{mg} / \mathrm{ml}$ with continuous infusion and $20 \mathrm{mg}$ tramadol HCL doses per press were adjusted with a 20-minute locking interval. The patient was instructed to press the button whenever he had pain. In addition, $800 \mathrm{mg}$ IV ibuprofen was administered as 4 times every 6 hours.

The patients were taken to the operating room and their electrocardiography (ECG), heart rate (HR), non-invasive blood pressure (NIBP) and peripheral oxygen saturation $(\mathrm{SpO} 2)$ values were monitorized. Peripheral vascular access was established with an 18-gauge intravenous cannula. In the induction of anesthesia, $2 \mathrm{mg} / \mathrm{kg}$ of propofol (Propofol Lipuro \%1 ampoule, B.Braun, Melsungen, Germany), $1 \mathrm{mcg} / \mathrm{kg}$ of fentanyl (Fentanyl amp 0,05 mg/ml, Jansenn, 
Belgium), $0.5 \mathrm{mg} / \mathrm{kg}$ of rocuronium (Esmeron flk $50 \mathrm{mg} / 5 \mathrm{ml}$ ) were given intravenously to induce unconsciousness and muscle relaxation, and then the patients were intubated. Anesthesia was maintained with Desflurane 6$7 \%$ (Suprane Liquid, Baxter, USA) $+50 \%$ oxygen $+50 \%$ air. According to the randomization result in Group 1 (Tramadol), Tramadol HCL was given continuous infusion at a concentration of $4 \mathrm{mg} / \mathrm{ml}$ via IV Patient Controlled Analgesia. Doses that could be administered $20 \mathrm{mg}$ of tramadol HCL at each push with a lock-in interval of 20 minutes were adjusted. The patient was instructed to press the button whenever he had pain. In Group2 800 mg IV ibuprofen was administered 30 minutes before the end of the operation. Patients were followed up by administering $800 \mathrm{mg}$ IV every 6 hours for 24 hours. The $800 \mathrm{mg}$ IV ibuprofen was administered as 4 times every 6 hours. In Group 3 (Ibuprofen + Tramadol), 30 minutes before the end of the operation, tramadol was administered via PCA at a concentration of $4 \mathrm{mg} / \mathrm{ml}$ with continuous infusion and $20 \mathrm{mg}$ tramadol HCL doses per press were adjusted with a 20-minute locking interval. The patient was instructed to press the button whenever he had pain. In addition, $800 \mathrm{mg}$ IV ibuprofen was administered 4 times every 6 hours.

At the end of the operation, $0.01-0.02 \mathrm{mg} / \mathrm{kg}$ atropine and $0.04-0.08 \mathrm{mg} / \mathrm{kg}$ neostigmine were administered for muscle relaxant antagonization, and all patients were admitted to the postoperative anesthesia care unit (PACU) after extubation.

Patients with hypersensitivity to the drugs to be used in the study or to the substances in their composition, pregnant women, patients with severe cardiac, pulmonary, hepatic and renal disease, patients with a history of chronic opioid use and chronic pain syndrome, patients with low socio-cultural and mental capacities, who cannot apply patient-controlled analgesia was excluded from the study. Demographic data (gender, age, weight, height, BMI, comorbidities) of all patients were recorded before the surgical procedure. Postoperative SAP, DAP, MAP, HR, VAS values at 30 minutes, 1st hour, 2nd hour, 4th hour, 8th hour, 12th hour, 18th hour and 24th hour; tramadol consumption, nausea, vomiting, and patient satisfaction at at 0-1, 1-12, 12-24 hours were evaluated and recorded. Patients with nausea and vomiting were treated with ondansetron (ZOFRAN ampoule IV $8 \mathrm{mg} / 4 \mathrm{mg} / \mathrm{ml}$ GlaxoSmithKline SpA, Italy) and, patients with rash and itching were treated with Pheniramine hydrogen maleate (Avil ampoule IM/IV 45.5 mg/2 ml Sandoz İlaç San. ve Tic. A.Ş. Turkey). When the VAS was above $4,0.05 \mathrm{mg} / \mathrm{kg}$ morphine (Morphine HCL® $0.01 \mathrm{~g} / \mathrm{ml} \mathrm{amp}$ Galen İlaç AŞ./ Turkey) in $100 \mathrm{ml}$ saline was administered intravenously as a rescue analgesic.

\section{Statistical analyses}

The information collected from the patients was entered into the SPSS 21.0 package program and statistical analyzes were made. Descriptive statistics of the variables (Frequency, Percentages, Mean \pm Standard Deviation, Median (interquartile range) were presented with tables. Three group comparisons were performed with one-way ANOVA test. Pairwise comparisons were continued with the post-hoc Bonferroni pairwise comparison test. For parametric repeated measures, repeated measures ANOVA test was applied.

Three group comparisons were performed with the Kruskal Wallis $\mathrm{H}$ test. For those with significant differences between the groups, pairwise comparisons were continued with Dunn-Bonferoni paired comparison test in order to determine which group the difference originated from. 
Pearson Chi-Square test or Fisher's exact test was used to compare categorical variables.

Value of $p<0.05$ was considered statistically significant. Data lists for each group were summarized with summary statistics.

\section{Results}

60 patients were included in the study. However, 8 patients whose operation was postponed due to the Covid-19 pandemic and 5 patients who were re-operated due to postoperative complications were excluded from the study. The study was completed with 47 patients, including 16 patients in Group 1, 16 patients in Group 2, and 15 patients in Group 3. There was no statistically significant difference between the groups in terms of age, weight, height, BMI, duration of surgery, duration of anesthesia, ASA classification score $(p>0.05)$ (Table 1).

When the resting VAS scores were compared, the resting VAS scores at each hour were found to be statistically significantly lower in Group 3 compared to Group 2 ( $p<0.05)$. The resting VAS score at the 4th hour in Group 3 was found to be statistically significantly lower compared to Group 1 ( $p<0.001)$. Resting VAS scores at the 8th, 12th, 16th, 20th and 24th hours were found to be statistically significantly lower in Group 1 compared to Group $2 \quad(p<0.001)$ (Figure 1). When tramadol consumption amounts were examined, it was determined that the amount of tramadol consumed in Group 3 was statistically lower in 0-1, 1-12, 12-24 hours and total consumption compared to Group 1 $(p<0.05)$ (Figure 2).

Table 1. Comparison of the parameters of the groups.

\begin{tabular}{|l|c|c|c|c|}
\hline Variables & $\begin{array}{c}\text { Group 1 } \\
\text { (Tramadol) }\end{array}$ & $\begin{array}{c}\text { Group 2 } \\
\text { (Ibuprofen) }\end{array}$ & $\begin{array}{c}\text { Group 3 } \\
\text { (Ibuprofen + Tramadol) }\end{array}$ & $p$-value \\
\hline Gender & $14(\% 87,5)$ & $13(\% 18,8)$ & $10(\%)$ & 0,35 \\
\hline \multicolumn{1}{|c|}{ Female } & $2(\% 12,5)$ & $3(\% 81,3)$ & $5(\% 33,3)$ & \\
\hline Age & $42,75 \pm 13,17$ & $40,13 \pm 11,13$ & $38,13 \pm 7,88$ & 0,508 \\
\hline Weight (kg) & $80,44 \pm 10,87$ & $80,25 \pm 16,45$ & $82,33 \pm 13,39$ & 0,898 \\
\hline Height (cm) & $159 \pm 4$ & $161 \pm 6$ & $162 \pm 6$ & 0,817 \\
\hline BMI (kg/m $)$ & $31,1 \pm 4,25$ & $30,67 \pm 4,67$ & $31,26 \pm 3,98$ & 0,923 \\
\hline ASA score & $6-10$ & $10-6$ & $9-6$ & 0,212 \\
\hline \multicolumn{1}{|c|}{$1 / 2$} & $181,56 \pm 33,25$ & $163,44 \pm 51,63$ & $190,33 \pm 28,88$ & 0,223 \\
\hline $\begin{array}{l}\text { Duration of anesthesia } \\
\text { (min.) }\end{array}$ & $164,38 \pm 34,25$ & $147,5 \pm 51,41$ & $172 \pm 29,14$ & 0,127 \\
\hline $\begin{array}{l}\text { Duration of surgery } \\
\text { (min.) }\end{array}$ & & & & \\
\hline
\end{tabular}

Values: $n=$ number of patients, $n(\%)$, given as average \pm standard deviation. BMI: Body Mass Index 


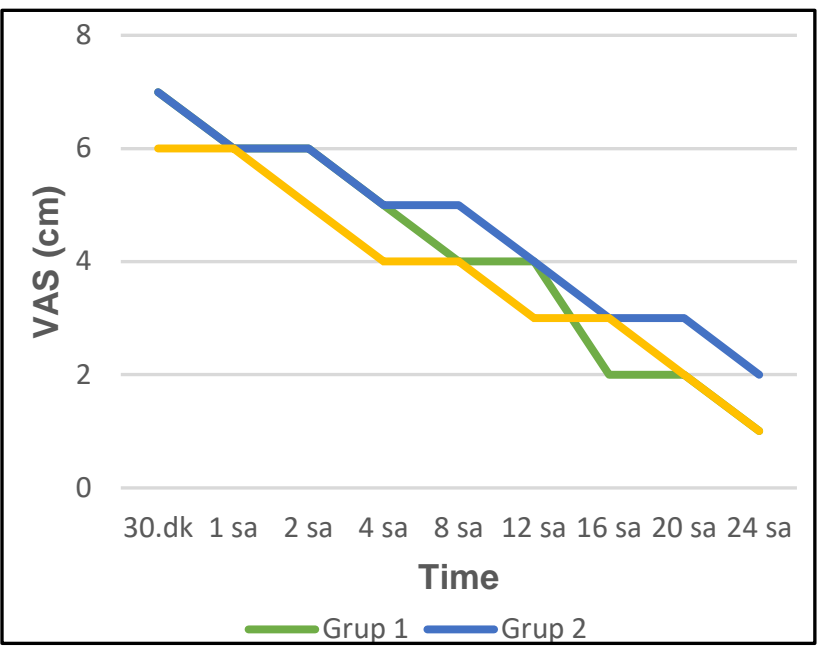

Figure 1. Resting VAS scores of the groups.

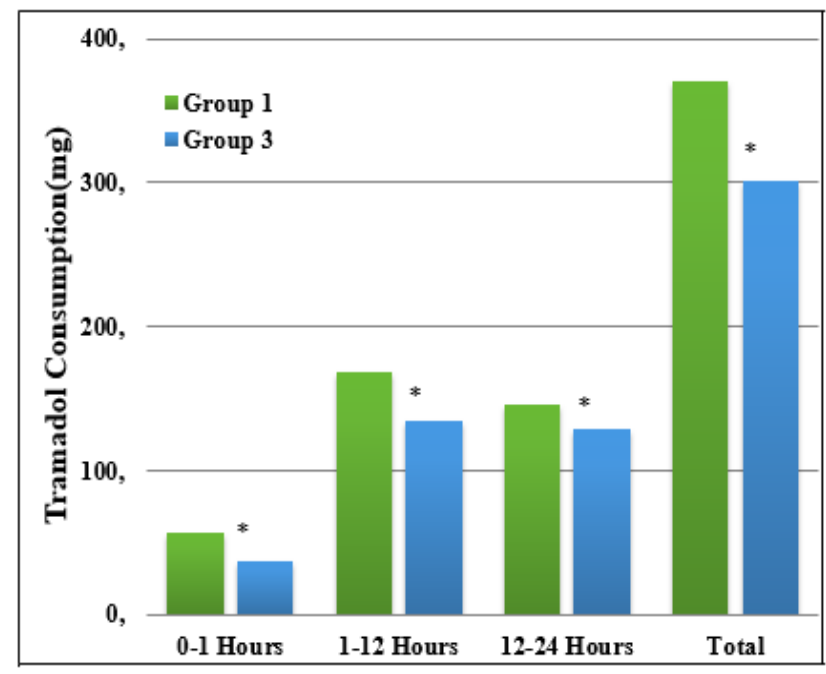

Figure 2. Tramadol Consumption Amount (mg).

*Statistically significant difference at $p<0.05$ significance level according to independent groups t-test.

There was no statistically significant difference between the groups in terms of the use of morphine as a rescue analgesia $(p>0.05)$. In terms of side effects, nausea was seen at a rate of $6.3 \%$ in the ibuprofen group, and at a rate of $50 \%$ in the tramadol group and $40 \%$ in the group in which tramadol and ibuprofen were administered together. When this rate was compared between the groups, it was found to be statistically lower in Group 2 compared to Group 1 and Group $3(p<0.05)$.

\section{Discussion}

This study showed that; Tramadol and IV ibuprofen given as analgesics after abdominoplasty operation alone can provide analgesia by reducing the postoperative VAS values. However, when tramadol and IV ibuprufen are used together, they provide analgesia by reducing VAS values more effectively and lead to less opioid consumption. In addition, the frequency of nausea and vomiting in IV ibuprofen administered patients is less than in opioid administered patients.

Abdominoplasty is one of the most painful procedures in plastic surgery. In recent years, the number of operations due to reconstruction after obesity and aesthetic reasons has been increasing. Moderate to severe pain lasting longer than 24 hours can be seen, usually due to the need for extensive tissue mobilization, folding of the smooth abdominal muscles for deformities of the myoaponeurotic layer, and intense liposuction [11]. If pain is not adequately controlled, it can lead to heart, lung and kidney problems due to metabolic, endocrine and inflammatory responses. In addition, it may lead to deterioration in patient comfort, delayed mobilization, prolongation of hospital stay and increased cost [12]. Traditional postoperative pain management often uses opioids. Although opioids provide satisfactory relief of moderate to severe pain, there are risks of respiratory depression, sedation, nausea, vomiting, constipation and addiction $[13,14]$. Therefore, clinical guidelines recommend multimodal analgesia, which includes reducing the dose and duration of opioid use, plus the use of non-opioid analgesics [14,15]. Ibuprofen is an NSAID drug that is frequently used as a part of multimodal analgesia, especially in the treatment of low and moderate pain. Compared to other NSAIDs, 
ibuprofen has a COX-1/COX-2 inhibition ratio of less than one. In this way, ibuprofen has a lower side-effect profile. With the widespread use of the IV form of ibuprofen, it has gained an important place among the agents used in postoperative analgesia [16]. The recommended dose of IV ibuprofen is 400-800 mg every six hours. The maximum daily dose is $3200 \mathrm{mg}$ [17]. Kroll et al. investigated the postoperative analgesic efficacy of IV ibuprofen in 319 patients undergoing abdominal hysterectomy. They reported that it provided more effective analgesia and faster ambulation time, was well tolerated and safe in the group given $800 \mathrm{mg}$ every 6 hours [18]. Martinez et al. investigated the efficacy and safety of IV ibuprofen in the treatment of postoperative pain in 206 patients undergoing abdominal and orthopedic surgery. They found that there was a significant decrease in VAS scores and total morphine consumption in the group in which ibuprofen was added as a part of multimodal analgesia compared to the group that was given only morphine. They reported that the use of $800 \mathrm{mg}$ IV ibuprofen every 6 hours in patients who will undergo abdominal surgery reduces morphine consumption and pain scores, reduces opioid-related side effects, and can be used effectively and safely [10]. Minkowitz et al. evaluated tramadol and morphine in terms of postoperative analgesia and side effect profile in their study, which included 370 patients who had abdominoplasty operation. When the postoperative analgesia and side effects were examined, they reported that the incidence of opioid-related side effects was lower in the tramadol group in terms of side effects with similar analgesic effects [19].

In our study, we preferred tramadol because of its similar analgesic effect and low side-effect profile. We found that VAS values were lower in the group that added ibuprofen to tramadol, similar to other studies. At the same time, we found that the addition of iburofen to the opioid reduced the frequency of side effects.

As a result; we believe that adding IV form of ibuprofen to opioids as part of multimodal analgesia provides adequate analgesia, reducing total opioid consumption and the incidence of opioid-related side effects.

Funding: The author(s) received no financial support for the research, authorship, and/or publication of this article.

Conflict of Interest: The authors declare that they have no conflict of interest.

Ethical statement: The study was approved by Bolu Abant Izzet Baysal University Clinical Studies Ethics Committee. (Date and number: 04/08/2020 and 2020/190).

\section{Open Access Statement}

This is an open access journal which means that all content is freely available without charge to the user or his/her institution under the terms of the Creative Commons Attribution NonCommercial License (https://creativecommons.org/licenses/by/4.0/). Users are allowed to read, download, copy, distribute, print, search, or link to the full texts of the articles, without asking prior permission from the publisher or the author.

Copyright (c) 2021: Author (s).

\section{References}

[1]Friedland JA, Maffi TR. MOC-PS(SM) CME article: Abdominoplasty. Plast Reconstr Surg. 2008;121(4 Suppl):1-11.

[2]Abo-Zeid MA, Al-Refaey AK, Zeina AM. Surgically-assisted abdominal wall blocks for analgesia after abdominoplasty: A prospective randomized trial. Saudi J Anaesth. 2018;12(4):593-98. 
[3]American Society of Anesthesiologists Task Force on Acute Pain Management. Practice guidelines for acute pain management in the perioperative setting: an updated report by the American Society of Anesthesiologists Task Force on Acute Pain Management. Anesthesiology. 2004;100(6):1573-81.

[4]Morales R Jr, Mentz H 3rd, Newall G, et al. Use of abdominal field block injections with liposomal bupivicaine to control postoperative pain after abdominoplasty. Aesthet Surg J. 2013;33(8):1148-53.

[5]Kurşun YZ, Yıldız F, Kaymaz Ö, et al. Ağrılı kanser hastalarının tedavisinde analjezik basamak tedavisinin yeri [Analgesic step ladder treatment in cancer patients with pain]. Agri. 2015;27(1):26-34.

[6]Hanna MN, Murphy JD, Kumar K, et al. Regional techniques and outcome: what is the evidence?. Curr Opin Anaesthesiol. 2009;22(5):672-77.

[7]Rathmell JP, Wu CL, Sinatra RS, et al. Acute post-surgical pain management: a critical appraisal of current practice, Reg Anesth Pain Med. 2006;31(4):1-42.

[8]Svensson CI, Yaksh TL. The spinal phospholipase-cyclooxygenase-prostanoid cascade in nociceptive processing. Annu Rev Pharmacol Toxicol. 2002;42:553-83.

[9]Kehlet H, Dahl JB. The value of "multimodal" or "balanced analgesia" in postoperative pain treatment. Anesth Analg. 1993;77(5):1048-56.

[10] Gago Martínez A, Escontrela Rodriguez B, Planas Roca A, et al. Intravenous Ibuprofen for Treatment of Post-Operative Pain: A Multicenter, Double Blind, PlaceboControlled, Randomized Clinical Trial. PLoS One. 2016;11(5):e0154004.
[11]Hurvitz KA, Olaya WA, Nguyen A, et al. Evidence-based medicine: Abdominoplasty. Plast Reconstr Surg. 2014;133(5):1214-21.

[12] Kubra Turkoglu, Isa Yildiz, Kutay Engin Ozturan, et al. Comparison of Analgesic Effects of Pure Bupivacaine and Morphine Added as Bupivacaine Adjuvant in USG Guided Adductor Canal Block Following Total Knee Arthroplasty. EJMI 2020;4(3):327-31.

[13] Stein C. New concepts in opioid analgesia. Expert Opin Investig Drugs. 2018;27(10):765-75.

[14] Singla NK, Skobieranda F, Soergel DG, et al. APOLLO-2: A Randomized, Placebo and Active-Controlled Phase III Study Investigating Oliceridine (TRV130), a G Protein-Biased Ligand at the $\mu$-Opioid Receptor, for Management of Moderate to Severe Acute Pain Following Abdominoplasty. Pain Pract. 2019;19(7):715-31.

[15] Wardhan R, Chelly J. Recent advances in acute pain management: understanding the mechanisms of acute pain, the prescription of opioids, and the role of multimodal pain therapy. F1000Res. 2017;6:2065.

[16]Erdogan Kayhan G, Sanli M, Ozgul U, et al. Comparison of intravenous ibuprofen and acetaminophen for postoperative multimodal pain management in bariatric surgery: A randomized controlled trial. J Clin Anesth. 2018 ;50:5-11.

[17] Southworth S, Peters J, Rock A, et al. A multicenter, randomized, double-blind, placebo-controlled trial of intravenous ibuprofen 400 and $800 \mathrm{mg}$ every 6 hours in the management of postoperative pain. Clin Ther. 2009;31(9):1922-35.

[18]Kroll PB, Meadows L, Rock A, et al. Multicenter, randomized, double-blind, 
placebo-controlled trial of intravenous ibuprofen (i.v.-ibuprofen) in the management of postoperative pain following abdominal hysterectomy. Pain Pract. 2011 11(1):23-32.

[19] Minkowitz H, Salazar H, Leiman D, et al. Intravenous Tramadol is Effective in the Management of Postoperative Pain Following Abdominoplasty: A Three-Arm Randomized Placebo- and ActiveControlled Trial. Drugs R D. 2020;20(3):225-36. 